\title{
Management of Remnant or Recurrent Lesions after Endoscopic Papillectomy
}

\author{
Ichiro Yasuda, Saito Kobayashi, Kosuke Takahashi, Sohachi Nanjo, Hiroshi Mihara, Shinya Kajiura, Takayuki Ando, Kazuto Tajiri, \\ and Haruka Fujinami \\ Third Department of Internal Medicine, University of Toyama, Toyama, Japan
}

Endoscopic papillectomy (EP) for ampullary adenomas achieves cure rates ranging from $76 \%$ to $90 \%$, and recurrence rates are as high as $33 \%$. If remnant or recurrent lesions after prior EP are endoscopically visible and are not suspected of intraductal extension into the biliary or pancreatic duct, repeated snaring and cutting can be performed until all visible lesions are completely resected. However, endoscopic ablative therapies, particularly argon plasma coagulation, can be attempted for tiny or uncertain remnant and recurrent lesions. In addition, intraductal radiofrequency ablation has recently been attempted for residual intraductal lesions after EP at several institutions. Although still under investigation, it has shown some promise. It might be offered as an alternative to surgery, particularly in patients who are unfit for surgery or those who refuse to undergo surgery. Clin Endosc 2020;53:659-662

Key Words: Ampullary adenoma; Argon plasma coagulation; Endoscopic papillectomy; Radiofrequency ablation

\section{INTRODUCTION}

Ampulla of Vater (AOV) tumors are increasingly detected because of the widespread use of esophagogastroduodenoscopy as a screening tool for gastric cancer and other gastrointestinal disorders. Most AOV tumors are adenomas. However, careful observation or complete resection is recommended because of their malignant potential and difficulty in discriminating them from early carcinomas. Focal carcinoma can be missed by endoscopic biopsy sampling, and is found only in resected specimens in $6 \%$ to $26 \%$ of the adenomas in patients undergoing papillectomy. ${ }^{1,2}$ Recently, endoscopic papillectomy (EP) has become a popular therapeutic option for the management of AOV adenomas because it is less invasive com-

Received: September 1, 2019 Revised: September 17, 2019

Accepted: September 17, 2019

Correspondence: Ichiro Yasuda

Third Department of Internal Medicine, University of Toyama, 2630 Sugitani, Toyama 930-0194, Japan

Tel: +81-76-434-7300, Fax: +81-76-434-5027, E-mail: yasudaich@gmail.com ORCID: https://orcid.org/0000-0002-6888-0310

(c) This is an Open Access article distributed under the terms of the Creative Commons Attribution Non-Commercial License (http://creativecommons.org/ licenses/by-nc/3.0) which permits unrestricted non-commercial use, distribution, and reproduction in any medium, provided the original work is properly cited. pared with surgical resection. Endoscopic treatment of AOV adenomas achieves cure rates ranging from $76 \%$ to $90 \%$ in patients without intraductal extension. ${ }^{1}$ Recurrence rates have been reported to be as high as $33 \%{ }^{3}$

\section{STANDARD ENDOSCOPIC TREATMENT STRATEGY OF AOV ADENOMAS}

If lesions can be ensnared completely, en bloc complete resection is generally performed. However, large lesions are more likely to be incompletely excised during the initial endoscopic procedure. Piecemeal or repeated resection is often performed for lesions $>2 \mathrm{~cm}$ or for cases in which visible neoplastic tissue remains after an attempted en bloc resection. In case of a visible remnant tumor after the initial snare cutting, repeated snaring can generally be performed until the complete visible remnant tumor is resected. However, endoscopic ablative therapies such as electrocoagulation and argon plasma coagulation (APC) can also be selectively performed at the discretion of the endoscopist for uncertain or tiny remnant lesions and for controlling immediate bleeding or preventing post-procedural bleeding. 


\section{TREATMENT STRATEGY FOR REMNANT OR RECURRENT LESIONS}

Evaluation of remnant lesions is not always easy immediately after EP because of bleeding, swelling, and the burn effect. Therefore, it is recommended that all patients who have undergone EP undergo surveillance endoscopy for the detection of remnant or recurrent lesions after 1 to 3 months. Residual or recurrent neoplastic tissue often grows across the scar after the resection. Some experts advocate endoscopic evaluation with biopsy of the scar. ${ }^{3}$ Varied post-treatment surveillance intervals have been suggested and surveillance is typically performed 1 to 6 months after EP. ${ }^{3}$ Repeat EP is generally performed for residual or recurrent lesions, unless intraductal extension is observed. However, various ablative therapies can also be attempted depending on the operator's preference and institutional facilities.

\section{ABLATIVE THERAPIES FOR REMNANT OR RECURRENT LESIONS}

Various endoscopic ablative therapies can be performed to destroy residual or recurrent superficial adenomas that cannot be removed during previously attempted snare resections. These include electrocoagulation using a monopolar or bipolar probe, APC, laser therapy, photodynamic therapy (PDT), and radiofrequency ablation (RFA) (Table 1). ${ }^{4}$ However, there have only been a few reports that evaluated the clinical outcomes of such ablative therapies for remnant or recurrent lesions.

APC is a type of non-contact thermal ablation in which a high-frequency current is applied to the target lesion. It is widely used for the treatment of endoscopic hemostasis or as an additional treatment after endoscopic resection. APC is the most frequently used ablative modality for residual or recurrent lesions after EP, given its widespread availability and superficial depth of tissue destruction. Nam et al. ${ }^{5}$ compared short- and long-term outcomes between the EP-with-addi-

Table 1. Endoscopic Therapies for Remnant or Recurrent Lesion after Endoscopic Papillectomy

\begin{tabular}{l}
\hline Snare resection \\
\hline Ablative therapies \\
Electrocoagulation \\
Argon plasma coagulation \\
Laser therapy \\
Photodynamic therapy \\
Radiofrequency ablation \\
\hline
\end{tabular}

tional-APC group and the EP-alone group using propensity score matching. Additional APC was selectively used at the discretion of the endoscopist for the control of immediate bleeding, prevention of post-procedural bleeding, or ablation of suspected microscopic remnant tumors. The bleeding rate was significantly lower in the EP+APC group than in the EPalone group. There was no significant difference in early adverse effects such as pancreatitis, cholangitis, and perforation between both groups. Recurrence rates were also compared and were not significantly different. Sakai et al. ${ }^{6}$ retrospectively investigated clinical outcomes in 45 cases with AOV neoplasms who had undergone EP. Local recurrence was observed in 3 of 20 cases with positive or uncertain resected margins and in 1 of 21 cases with negative resected margins. However, all 4 recurrent cases ( 3 adenomas and 1 borderline lesion) were successfully treated with APC. There was no local or lymph node recurrence after APC, with follow-up periods of 56 to 133 months. There is no consensus regarding settings or power levels for APC. Pancreatic stents are usually placed before ablating the tissue around the pancreatic orifice. ${ }^{3}$ However, pathological evaluation is impossible after such ablative therapies.

\section{LATERAL SPREADING AND INTRADUCTAL LESIONS}

Both lateral spreading and intraductal lesions may be unfavorable for endoscopic resection. Lateral- spreading lesions often require repeat piecemeal snare resection. Moreover, extension of AOV adenomas into the common bile duct or pancreatic duct is challenging to treat endoscopically and is generally considered a contraindication to endoscopic therapy. Limited visualization and inability to accurately target intraductal lesions make endoscopic treatment difficult. Moreover, it is sometimes difficult to recognize the lesion before resection, even with endoscopic retrograde cholangiopancreatography, endoscopic ultrasonography, and intraductal ultrasonography. Intraductal remnant lesions are sometimes detected after EP.

Klein et al. ${ }^{7}$ retrospectively compared the clinical outcomes of EP for lateral spreading lesions, which were defined as extending $>10 \mathrm{~mm}$ beyond the ampullary mound, with lesions confined to the ampullary mound. Although lateral spreading lesions showed higher rates of intraprocedural bleeding (50\% vs. $24.7 \%$ ) and delayed bleeding ( $25.0 \%$ vs. $12.3 \%)$, both groups of lesions had similar rates of histologically proven recurrence at the first surveillance (16.4\% vs. $17.9 \%)$. In a retrospective cohort study, van der Wiel et al. ${ }^{8}$ compared the clinical outcomes of EP for lateral spreading/intraductal extending ade- 
nomas with those confined to the ampulla. A lateral spreading adenoma was defined as an adenoma that extended laterally $>10 \mathrm{~mm}$ along the surface of the gastrointestinal tract, and it was removed in a piecemeal fashion. The successful resection rate of lateral spreading adenomas was comparable to that of adenomas confined to the ampulla. Intraductal extension of adenomas had less favorable outcomes with EP. Bohnacker et al. ${ }^{9}$ reported that EP was less curative and that surgery was required more frequently in cases with intraductal growth than in cases without intraductal growth. In their analysis of factors for complete resection by EP, Ridtitid et al. ${ }^{10}$ reported that intraductal involvement was significantly associated with lower odds of achieving complete resection.

Recently, some endoscopists attempted to expand the indication for endoscopic therapy to AOV adenomas with intraductal extension. However, as previously mentioned, limited visualization and the inability to accurately target intraductal lesions made endoscopic treatments difficult. To overcome such problems, a balloon-tipped catheter was used to expose intraductal adenomas and permit complete endoscopic resection. Kim et al. ${ }^{11}$ reported their experience of EP with an extraction balloon catheter for an unexposed ampullary adenoma. They reported the successful exposure of the ampullary mass to the duodenal side using an extraction balloon catheter; snare resection was then performed on the exposed ampullary mass, and APC was additionally used at the resected area to ablate any remnant adenomatous tissue. Dzeletovic et al. ${ }^{12}$ used a biliary dilation balloon catheter to visualize the intraductal lesion. After visualization of the intraductal lesion, the authors performed snare resection and/or treated it with various thermal therapies including a heater probe, APC, PDT, and RFA.

\section{INTRADUCTAL RFA FOR INTRADUCTAL LESIONS}

Intraductal biliary RFA is an ablative therapy used to treat malignant biliary strictures and tumor ingrowth into biliary self-expandable metal stents. Recently, there have been several reports of RFA therapy for intraductal extension of AOV adenomas (Table 2). Valente et al. ${ }^{13}$ reported three cases with ampullary adenoma that were treated with RFA: one had intraductal recurrence after EP and the other two had intraductal adenoma with jaundice. The case with intraductal recurrence showed no recurrence with RFA at the 26-month follow-up. The remaining two cases with jaundice had successful prolonged palliation of jaundice at the 12- and 36-month follow-up, respectively. Mehendiratta et al. ${ }^{14}$ also reported a case where RFA was successful in eradicating residual ampullary adenoma at the biliary orifice after performing EP in the same year. Rustagi et al. ${ }^{1}$ reported clinical outcomes in a case series where complete intraductal adenoma eradication was achieved in 12 of the 13 assessable patients (92\%) using endoscopic RFA. Adverse events occurred in 6 of 14 patients (43\%) and included symptomatic or asymptomatic biliary strictures and retroduodenal abscess. However, all patients successfully recovered via endoscopic treatments. Most recently, Camus et al. ${ }^{15}$ evaluated the efficacy and safety of intraductal RFA for the treatment of residual intraductal adenoma after EP in a prospective multicenter study. Twenty patients with a histologically proven endobiliary remnant adenoma were included in this study. The rates of occurrence of residual neoplasia were $15 \%$ and $30 \%$ at 6 and 12 months, respectively. Two patients (10\%) were referred to undergo surgery because of suspected or confirmed malignancy. Eight patients (40\%) experienced at least one adverse event, which included mild pancreatitis, melena, cholangitis, and asymptomatic biliary strictures, between RFA and the 12-month follow-up. However, no major adverse events occurred.

Table 2. Radiofrequency Ablation for Intraductal Extension of Ampulla of Vater Adenoma

\begin{tabular}{|c|c|c|c|c|}
\hline Study & $n$ & $\begin{array}{l}\text { Treatment } \\
\text { success (\%) }\end{array}$ & Follow-up results & Adverse events \\
\hline Valente et al. $(2015)^{13}$ & 3 & $100 \%$ & $\begin{array}{l}\mathrm{F} / \mathrm{U} \text { period of } 12 \mathrm{mo}, 26 \mathrm{mo}, 36 \mathrm{mo} \\
\text { Recurrence: none }\end{array}$ & None \\
\hline Mehendiratta et al. $(2015)^{14}$ & 1 & $100 \%$ & $\mathrm{~F} / \mathrm{U}$ data is not available & None \\
\hline Rustagi et al. $(2017)^{1}$ & 14 & $92 \%$ & $\begin{array}{l}\text { Median F/U of } 16 \text { mo }(5-46 \mathrm{mo}) \\
\text { Recurrence: } 1 \text { case }\end{array}$ & $\begin{array}{l}43 \% \text { ( } 2 \text { symptomatic, } 3 \text { asymptomatic } \\
\text { biliary stricture, } 1 \text { retroduodenal abscess) }\end{array}$ \\
\hline Camus et al. $(2018)^{15}$ & 20 & $100 \%$ & $\begin{array}{l}\text { Recurrence: } 3 \text { cases }(15 \%) \text { at } 6 \mathrm{mo}, 6 \\
\text { cases }(30 \%) \text { at } 12 \mathrm{mo}\end{array}$ & $\begin{array}{l}40 \% \text { ( } 4 \text { abdominal pain, } 3 \text { pancreatitis, } 1 \\
\text { bleeding, } 4 \text { cholangitis, } 4 \text { asymptomatic } \\
\text { biliary stricture) }\end{array}$ \\
\hline
\end{tabular}

F/U, follow-up. 
These results suggest that intraductal RFA of residual intraductal lesions after EP can be offered as an alternative to surgery, particularly in patients who are unfit for surgery or those who refuse to undergo surgery.

\section{CONCLUSIONS}

In cases with visible remnant or recurrent lesions after index EP, repeat snaring and cutting can generally be performed until all visible lesions are completely resected. However, endoscopic ablative therapies, particularly APC, can be attempted for tiny or uncertain remnant or recurrent lesions. In addition, intraductal RFA has recently been attempted for residual intraductal lesions after EP at several institutions. Although it is still under investigation, it has shown some promise. It might be offered as an alternative to surgery, particularly in patients who are unfit for surgery or those who refuse to undergo surgery.

Conflicts of Interest

The authors have no financial conflicts of interest.

\section{ORCID}

Saito Kobayashi: https://orcid.org/0000-0003-0286-2037

Kosuke Takahashi: https://orcid.org/0000-0003-2361-5043

Sohachi Nanjo: https://orcid.org/0000-0002-5826-2893

Hiroshi Mihara: https://orcid.org/0000-0002-8427-2868

Shinya Kajiura: https://orcid.org/0000-0003-4920-5130

Takayuki Ando: https://orcid.org/0000-0001-8369-8536

Kazuto Tajiri: https://orcid.org/0000-0002-2373-8601

Haruka Fujinami: https://orcid.org/0000-0003-4410-6272

\section{REFERENCES}

1. Rustagi T, Irani S, Reddy DN, et al. Radiofrequency ablation for in- traductal extension of ampullary neoplasms. Gastrointest Endosc 2017;86:170-176

2. Kang SH, Kim KH, Kim TN, et al. Therapeutic outcomes of endoscopic papillectomy for ampullary neoplasms: retrospective analysis of a multicenter study. BMC Gastroenterol 2017;17:69.

3. ASGE Standards of Practice Committee, Chathadi KV, Khashab MA, et al. The role of endoscopy in ampullary and duodenal adenomas. Gastrointest Endosc 2015;82:773-781.

4. Espinel J, Pinedo E, Ojeda V, Guerra Del Río M. Endoscopic ampullectomy: a technical review. Rev Esp Enferm Dig 2016;108:271-278.

5. Nam K, Song TJ, Kim RE, et al. Usefulness of argon plasma coagulation ablation subsequent to endoscopic snare papillectomy for ampullary adenoma. Dig Endosc 2018;30:485-492.

6. Sakai A, Tsujimae M, Masuda A, et al. Clinical outcomes of ampullary neoplasms in resected margin positive or uncertain cases after endoscopic papillectomy. World J Gastroenterol 2019;25:1387-1397.

7. Klein A, Qi Z, Bahin FF, et al. Outcomes after endoscopic resection of large laterally spreading lesions of the papilla and conventional ampullary adenomas are equivalent. Endoscopy 2018;50:972-983.

8. van der Wiel SE, Poley JW, Koch AD, Bruno MJ. Endoscopic resection of advanced ampullary adenomas: a single-center 14-year retrospective cohort study. Surg Endosc 2019;33:1180-1188.

9. Bohnacker S, Seitz U, Nguyen D, et al. Endoscopic resection of benign tumors of the duodenal papilla without and with intraductal growth. Gastrointest Endosc 2005;62:551-560.

10. Ridtitid W, Tan D, Schmidt SE, et al. Endoscopic papillectomy: risk factors for incomplete resection and recurrence during long-term follow-up. Gastrointest Endosc 2014;79:289-296.

11. Kim JH, Moon JH, Choi HJ, et al. Endoscopic snare papillectomy by using a balloon catheter for an unexposed ampullary adenoma with intraductal extension (with videos). Gastrointest Endosc 2009;69:14041406.

12. Dzeletovic I, Topazian MD, Baron TH. Endoscopic balloon dilation to facilitate treatment of intraductal extension of ampullary adenomas (with video). Gastrointest Endosc 2012;76:1266-1269.

13. Valente R, Urban O, Del Chiaro M, et al. ERCP-directed radiofrequency ablation of ampullary adenomas: a knife-sparing alternative in patients unfit for surgery. Endoscopy 2015;47 Suppl 1:E515-E516.

14. Mehendiratta V, Desilets DJ. Use of radiofrequency ablation probe for eradication of residual adenoma after ampullectomy. Gastrointest Endosc 2015;81:1055-1056.

15. Camus M, Napoléon B, Vienne A, et al. Efficacy and safety of endobiliary radiofrequency ablation for the eradication of residual neoplasia after endoscopic papillectomy: a multicenter prospective study. Gastrointest Endosc 2018;88:511-518. 